The following pages constitute the final, accepted and revised manuscript of the article:

Holmqvist, Fredrik and Stridh, Martin and Waktare, Johan E P and Brandt, Johan and Sörnmo, Leif and Roijer, Anders and Meurling, Carl J

"Rapid fluctuations in atrial fibrillatory electrophysiology detected during controlled respiration."

Am J Physiol Heart Circ Physiol. 2005 Aug;289(2):H754-60.

Publisher: American Physiological Society

Use of alternative location to go to the published version of the article requires journal subscription.

Alternative location: http://dx.doi.org/10.1152/ajpheart.00075.2005 


\section{Rapid Fluctuations in Atrial Fibrillatory Electrophysiology Detected during Controlled Respiration}

Fredrik Holmqvist, Martin Stridh*, Johan EP Waktare†, Johan Brandtł , Leif Sörnmo*, Anders Roijer, Carl J Meurling

D epartment of Cardiology, L und U niversity H ospital, L und, Sweden, "D epartment of $E$ lectroscience, L und Institute of T echnology, L und Sweden, ${ }^{\dagger} \mathrm{C}$ ardiac D epartment, Bladk pool V idtoria $\mathrm{H}$ ospital, U nited Kingdom and ₹D epartment of Thoracic Surgery, L und U niversity H ospital, L und, Sweden

Running Head: Controlled Respiration and AF Electrophysiology

\section{Contact information:}

Dr Fredrik Holmqvist

Dept of Cardiology

Lund University Hospital $\quad$ Tel: +46-(0) 46-17 3518

SE-221 85 Lund

Fax: +46-(0) 46-15 7857

SWEDEN

E-mail: $\quad$ Fredrik.Holmqvist@ kard.lu.se 


\section{AbStract}

Introduction: Heart rate during sinus rhythm is modulated through the autonomic nervous system generating short-term oscillations. The high-frequency components in these oscillations are associated with respiration, causing sinus arrhythmia, mediated by the parasympathetic nervous system. The purpose of this study was to evaluate whether slow controlled respiration causes cyclic fluctuations in the frequency of the fibrillating atria.

Methods and Results: Eight patients (four female; median age 63 years, range 53 to 68) with chronic atrial fibrillation (AF) and $3^{\text {rd }}$ degree AV block treated by permanent pacemaker were studied. Electrocardiogram was recorded during baseline rest, during $0.125 \mathrm{~Hz}$ frequency controlled respiration and finally during controlled respiration after full vagal blockade. Fibrillatory frequency was calculated using frequency analysis of the fibrillatory ECG (FAFECG ) for overlapping $2.5 \mathrm{~s}$ segments and spectral analysis of the resulting frequency trend was perfomred to determine the spectrum of variations of fibrillatory frequency.

Normalized spectral power at respiration frequency increased significantly during controlled respiration from 1.4 (0.76 to 2.0) (median and range) at baseline to 2.7 (1.2 to 5.8$)$ ( $p=0.01$ ). Following vagal blockade the power at respiration frequency decreased to $1.2(0.23$ to 2.8) ( $p=$ $0.01)$.

Conclusion: Controlled respiration causes cyclic fluctuations in the atrial fibrillatory frequency in patients with long duration AF. This phenomenon seems to be related to parasympathetic modulations of the atrial fibrillatory refractory period.

Keywords: Atrial fibrillation, Autonomic nervous system, Spectrum analysis, Non-invasive 


\section{INTRODUCTION}

Cyclic fluctuations in heart rate during sinus rhythm vary in response to a range of physiological regulatory systems. These fluctuations have been utilized to study autonomic regulation of human cardiovascular physiology. $(2,12,28)$ The origin of variations in the sinus interval is not fully explained, but appears to be predominantly determined by interactions between the autonomic nervous system, hormonal efferent systems and cardiac pacemaker cells.(12, 28) Analysis of heart rate variability by spectral methods (frequency domain analysis) is widely used to study autonomic tone and variations thereof. For example, fluctuations in the so-called highfrequency band (HF, 0.15 to $0.4 \mathrm{~Hz}$ ) correspond to normal respiratory frequencies and are thought to reflect parasympathetic tone.(26) These fluctuations have been shown to be abolished by parasympathetic withdrawal.(1, 2, 28)

Although variations in beat-to-beat intervals (i.e. RR intervals) are usually examined in frequency domain analysis studies, it is assumed that during sinus rhythm the variability of heart rate is determined by changes in autonomic input to the sino-atrial node (i.e. it is assumed that variations in the AV interval do not significantly influence total heart rate variation). Studies on heart rate variability in settings outside of sinus rhythm are sparse, but occasional studies during atrial tachycardia(15) and atrial fibrillation $(\mathrm{AF})(34,35)$ have been performed. These utilized analysis of RR interval data, which represents a potential significant weakness.(8) D uring AF rhythmic fluctuations in RR intervals are potentially determined by both AV-nodal conduction and atrial input frequency.(23) Thus, spectral analysis of RR intervals during AF cannot be assumed to reflect solely or predominantly atrial events as it may be primarily determined by AV nodal factors.

This study set out to explore whether in patients with atrial fibrillation, vagal induced changes in atrial electrophysiology can be detected during rhythm-controlled respiration. This is a time frame much shorter than previously examined for autonomic influences on refractoriness. We utilized time-frequency analysis,(14, 16, 24, 27, 32) which examines atrial electrophysiological 
changes rather than the $\mathrm{RR}$ interval.

\section{MeThODS}

\section{Study population}

Patients with permanent $\mathrm{AF}$ and complete heart block treated by permanent pacemaker were recruited. Exclusion criteria were pharmacological treatment with sympathomimetic or anticholinergic drugs, AF duration exceeding three years, or clinical conditions that could affect the autonomic nervous system, such as diabetes, hyperthyroidism, alcohol abuse, smoking or recent cardiovascular or cerebrovascular events. All patients gave written informed consent; the study was approved by the local E thics Committee and complied with the Declaration of Helsinki.

\section{Study Protocol and Data Acquisition}

In line with recommended practice for autonomic studies, all studies were performed during the morning and patients were instructed to abstain from eating for four hours and from caffeine for 24 hours prior to commencing the study. Cardiovascular drugs, other than direct sympathomimetic or anti-cholinergic drugs, were not discontinued. On arrival the patients' pacemakers were programmed to pace at $60 \mathrm{bpm}$ in unipolar VOO mode for the duration of the study.

Following the attachment of ECG electrodes and other preparation, patients were rested supine for 15 minutes in a quiet, temperature-controlled room. Electrocardiogram acquisition was then begun, and five minutes of baseline data was acquired. Subsequently, controlled respiration with four seconds inspiratory and four seconds expiratory phase duration was begun using auditory guidance (i.e. eight second cycles, respiratory frequency $=0.125 \mathrm{~Hz}$ ) and a second five-minute period of data for analysis was acquired once the patient was in a stable synchronized respiratory pattern. Finally full vagal blockade was induced by intravenous administration of atropine (0.02 $\mathrm{mg} / \mathrm{kg}$ ). After a five minute interval, $0.125 \mathrm{~Hz}$ controlled respiration was again commenced and 
a final five-minute period of ECG for analysis was acquired. Real time ECG was monitored throughout the study and blood pressure was manually measured every minute.

\section{Data Analysis}

\section{(A) ECG ACQUiSiTION}

A standard 12-lead ECG was acquired using a custom made optically isolated PC card (Siemens Elema AB, Solna, Sweden). The digital signal (1 kHz sampling rate, 16 bit analogue-to-digital conversion, $0.6 \mu \mathrm{V}$ amplitude resolution) was transferred to a personal computer, where the data was written to a file for subsequent off-line processing. Electrocardiogram signal acquisition was continuous throughout the study, but the periods for subsequent analysis were noted at the time of recording.

\section{(B) Pacing SpIKe ANd QRST Removal}

The initial stage comprised identification and digital subtraction of the unipolar pacing spike. Subsequently QRST cancellation was performed using a spatiotemporal approach(33) which involves multiple templates, allowing an improved matching to each individual complex and leaving less ventricular residua than conventional processing.

In this study, only data from lead V1 was used for further analysis, although V2 and V3 data were used in the QRST cancellation process.

\section{(C) Frequency anAlysis to detect FluCtuations at Respiratory CyCle LENGTHS}

A new method for fibrillatory frequency $(\mathrm{FF})$ trend estimation was used based on the logarithmic Fourier transform of overlapping (one every second) 2.56 second segments of 'atrial fibrillatory ECG '.(32) An example of the resulting time-frequency distribution is shown in Figure 1d. The frequency estimation was performed by aligning the spectrum of each new signal segment to a template spectrum with known main peak position. The advantage with such a procedure is that the entire energy of the signal (both fundamental frequency and harmonic pattern representing the rate and waveform shape of the signal, respectively) is used to obtain detailed frequency 
estimation. Estimation accuracy was ensured by requiring that both the peak magnitude and the ratio of the peak magnitude to the noise level of the spectrum exceeded certain thresholds. For each new spectrum, a template spectrum was formed by averaging frequency-aligned versions of previous spectra. All frequency estimates were used to provide a time series (see the frequency trend in Figure 1e) for a second spectral analysis using the fast Fourier transform (FFT) to detect fluctuations of the peak frequency value within the band 0.04-0.4 Hz see Figure $1 \mathrm{f}$ for an example of such modulation spectra. This range was chosen such that it corresponds to the range of the conventionally tested high and low frequency bands (HF, $0.150 .4 \mathrm{~Hz}$ and LF, 0.04 $0.15 \mathrm{~Hz}$ respectively) examined in heart rate variability studies, and contains the frequency of interest $(0.125 \mathrm{~Hz})$. The spectra were estimated from segments of five minute duration from each of the three intervals of interest for analysis, namely, the initial period of quiet rest, baseline (B), the period of controlled respiration (CR) and, finally, the period of controlled respiration post-atropine administration (PA).

Figure 1 illustrates the process from ECG via 'residual ECG' to final spectral analyses.

\section{Post-Processing Analyses and Statistics}

From each power spectrum was calculated: total power (0.04-0.4 Hz); low frequency power (0.04-0.15 Hz); high frequency power $(0.15-0.4 \mathrm{~Hz})$; and power at the frequency of controlled respiration $(0.125 \mathrm{~Hz})$.

All values are expressed as median and range. Wilcoxon matched pairs test was used for comparison between paired samples. Spearman ranked correlation coefficient was used elsewhere. A p $<0.05$ was considered statistically significant. All statistical analyses were performed using STATISTICA for Windows version 6.1 (StatSoft, Inc., Tulsa, OK, USA).

\section{Results}

\section{Study Population}


Eight patients (four female, median age 63 years, range 53 to 68) were included. Four patients were taking RAAS-inhibitors, one patient each was taking a $\beta$-blocker and a calcium channel antagonist, two patients were not using any heart active drug. Echocardiography demonstrated a median left atrial diameter of $42 \mathrm{~mm}$ (32 to 53) and a median ejection fraction of $55 \%$ (35 to 55). The median AF duration was 17 months (range five to 32 months, defined as the elapsed time since last documented SR) and the patients had undergone a median of nine prior cardioversions (range 4 to 26) (Table 1).

\section{Data Availability}

All patients were able to satisfactorily perform the rhythm-controlled respiration and all provided recordings were suitable for analysis.

\section{Population Obsenvations}

The median FF of patients at baseline was $6.9 \mathrm{~Hz}(6.1$ to $8.2 \mathrm{~Hz})$, with controlled respiration 7.0 $\mathrm{Hz}(6.0$ to $8.2 \mathrm{~Hz}, \mathrm{p}=\mathrm{NS}$ ) and following atropine injection $6.8 \mathrm{~Hz}$ (6.1 to $8.1 \mathrm{~Hz}, \mathrm{p}=\mathrm{NS}$ ). Power at the frequency of respiration $\left(\mathrm{P}_{0.125}\right)$ rose significantly during controlled respiration, from 0.15 $\mathrm{ms}^{2}(0.06$ to 0.25$)$ at baseline, to $0.36 \mathrm{~ms}^{2}(0.11$ to 0.58$)(\mathrm{p}=0.01)$. Following vagal blockade the $\mathrm{P}_{0.125}$ decreased to $0.13 \mathrm{~ms}^{2}(0.02$ to 0.42$)(\mathrm{p}=0.02)$, which was not significantly different compared to baseline.

Inspection of full spectra demonstrated that there was considerable but variable leakage of low frequency noise into the region of interest. To correct for the significant variability in total spectral power, the data were modeled by normalizing for this value. The resultant trends were similar (Table 2). The ratio of $\mathrm{P}_{0.125}$ to 'high frequency power' $(0.15-0.4 \mathrm{~Hz})\left(\mathrm{P}_{0.125} / \mathrm{P}_{\mathrm{HF}}\right)$ was found to best reflect actual shifts in power and also corrected for the absolute pollution of the spectrum. $\mathrm{P}_{0.125} / \mathrm{P}_{\mathrm{HF}}$ rose significantly during controlled respiration from 1.4 (0.76 to 2.0) at baseline to $2.7(1.2$ to 5.8$)(p=0.01)$ and fell to $1.2(0.23$ to 2.8$)(p=0.01)$ following atropine administration (figure 2). There was no significant difference between the baseline and postatropine $\mathrm{P}_{0.125} / \mathrm{P}_{\mathrm{HF}}(\mathrm{p}=0.40)$. There were no significant changes in other measured parameters. 


\section{Obsenvations in Individual Patients}

The response to controlled respiration was heterogeneous. Although all patients increased the $\mathrm{P}_{0.125} / \mathrm{P}_{\mathrm{HF}}$ during controlled respiration followed by a decrease after vagal blockade, the amount of response was variable (table 3). A spectrum from a single patient is illustrated in figure 3. In this patient, and in some but not all of the other patients, there appears to be significant low frequency spectral power exhibited in the low frequency band. Some of this energy might represent artifacts, but at present quantification of absolute power in both the low and high frequency band, as can be done during sinus rhythm, is not validated. No differences in patient characteristics in terms of age, AF-duration, LA-diameter, previous cardioversions, heart-drugs and other diseases could be found between marked responders and the less responsive patients.

\section{Discussion}

\section{Comparison of dynamic changes in the electrophysiologic properties of the fibrillating atria to other scenarios}

It is well known that fluctuations in heart rate during sinus rhythm are mainly determined by autonomic effects on the sino-atrial node. Specifically increased sympathetic tone increases and parasympathetic tone decreases the depolarization frequency of the specialized atrial pacemaker cells by respectively increasing and decreasing the rate of the spontaneous diastolic depolarization. $(2,6)$ However, the situation in the fibrillating atria is fundamentally different. The cycle length is the sum of the atrial myocyte effective refractory period, any possible excitable gap that may exist during $\operatorname{AF}(3,19)$ and the action potential up-stroke time, which is related to the conduction velocity. Fibrillatory frequency is the inverse of the fibrillatory cycle length. Thus, rhythmic fluctuations in atrial FF may result from dynamic changes in the refractory period, as well as changes in the conduction velocity or of the excitable gap.

The derived parameter of the FAF-ECG method, dominating atrial cycle length (D ACL, inverse 
of FF), from lead V1 has been shown to closely correlate to an invasively measured spatial mean of right atrial free wall cycle length.(14) This in turn has been shown to reflect atrial refractoriness. $(7,18,36)$ In this study FF is used as an index of atrial refractoriness. While enhanced parasympathetic tone prolongs the ventricular refractory period(17) it has the opposite affect in the atria during sinus rhythm.(17, 21, 31) The effect on atrial myocardium during AF is less studied but the evidence that exists, suggest that acetylcholine and enhanced vagal tone shortens the effective refractory period(16, 34) as it does during sinus rhythm. Consequently, enhanced vagal tone would lead to a higher fibrillation frequency, this could however not be verified in this study.

The response of vagal discharge is believed to be inhomogeneous, as the right atrium has more extensive parasympathetic innervation than the left atrium.(22, 37) This is consistent with the response of acetylcholine administration or vagal stimulation, demonstrating a more marked shortening of the refractory period in the right atria than in the left atria.(37), (31)

Experimental studies are limited but those available have not shown an effect of acetylcholine on conduction velocity.(20, 31)

\section{Mechanism of Shift in Spectral Power in Response to Slow Controlled Respiration and}

\section{Attenuation by Atropine}

Physiologically the atrial refractory period adapts automatically to changes in heart rate (i.e. depolarization rate). These changes occur immediately.(11) The autonomic nervous system and cardioactive drugs may also alter the electrophysiological properties of the atria. $(24,31)$ It has been demonstrated in previous experimental studies that cholinergic stimulation leads to a response within milliseconds, in contrast to the marked delay of response in the sympathetic modulation.(30) Moreover, it is well known that the length of the monophasic action potential can show rapid changes (i.e. beat to beat changes) even during high rate atrial depolarizations.(29) Thus, we conclude that it is theoretically possible for the atrial FF (i.e. the atrial refractory period) to be modulated at frequencies corresponding to respiration. 
The shifts in spectral power after atropine administration occurred without any changes in respiration pattern, ventricular rate, blood pressure and body posture or body movements. Finally, although parasympathetic modulation was specifically examined in this study, the human autonomic nervous system is in practice a complex interaction. Simultaneous afferent inputs occur from both sympathetic and parasympathetic limbs and are influenced by the central nervous system modulation. However the methodology employed has demonstrated a detectable role of parasympathetic efferents during longstanding AF Atrial stretch(5) may also have been involved; cyclic change in left and right atrial pressure would have been accentuated by slow breathing. A direct effect of stretch on atrial electrophysiology was disproved as a mechanism for our observations by its abolition with atropine. This indicates that reflex arches involving cholinergic receptors are involved. It is likely that the efferent limb of these arches is parasympathetic, but an involvment of baroreceptors and sympathetic fibres in the afferent limb can not be excluded.

\section{Preserved Dynamic Electrophysiological Changes in Chronic AF and Possible Mechanisms for Inter-Patient Variability}

Two very interesting aspects of the present study are firstly the fact that dynamic changes in atrial fibrillatory rhythm were detectable among patients with long duration AF, and secondly the observed inter-patient variation. All patients had long duration of AF and thus by current understanding, electrical remodeling would be expected to be 'complete'.(4, 13) The degree of spectral power shift to $0.125 \mathrm{~Hz}$ with controlled respiration was variable.

Previous studies have shown that following pharmacological interventions (and autonomic modulation) the change in FF is more pronounced in those who have a lower initial value.(24, 25) This implies that the atrium is only susceptible to modulation if the FF is low. However there was no such trend seen in the present study.

The present study is too small and the population too heterogeneous to draw conclusions regarding the importance of the above factors, but the variable preservation of responsiveness to 
autonomic stimuli is an important observation.

\section{Methodological issues and Study limitations}

Although all patients had long duration AF and complete heart block, the population was heterogeneous in ways which may be relevant. Complete heart block and AF are associated with, or directly caused by, a range of conditions such as congestive heart failure, other heart diseases, and with advanced age. All of these conditions are associated with attenuation of parasympathetic tone(10) and some of which were present in our patients. Conversely, half the patients in our study were taking RAAS inhibitors, and blockade of the renin-angiotensin system is known to increase the activity in the low-frequency band and to decrease the fluctuations at respiratory frequencies. $(1,2) 0$ ne patient was taking a beta-blocker, which has been shown to shift the frequency distribution towards higher frequencies,(9) although the exact effects are complex the shift may be induced by augmentation of vagal tone.

We excluded conditions and drugs which might have abolished autonomic modulations, but this compromise was made for logistical (patient recruitment) and ethical reasons (inadvisability of drug withdrawal in elderly patients with cardiac co-morbidity and without gain from participation in our study).

In this study we estimated changes in atrial FF using time-frequency analysis, which is an indirect assessment of atrial refractoriness. This method cannot discriminate between changes in atrial refractoriness and conduction velocity; the latter, however, is unlikely to change after atropine administration. The response of conduction velocity to controlled, slow respiration is uncertain, but since atropine attenuated the induced change (it is assumed that atropine does not affect the conduction velocity), it is likely that the observed change in atrial refractoriness is genuine. Time-frequency analysis from the V1 lead correlates to the fibrillatory cycle length of the right atrial free wall, and therefore direct deductions about the rest of the atria can not be made. Equally, this study recruited patients with longstanding AF. Therefore inferences about shorter duration AF can not be made, although it would be expected that the dynamic responsiveness of 
less re-modeled atria would be more pronounced.

The respiration was controlled by the use of auditory guidance but the definite respiration frequency was not objectively assessed during the study. Therefore it is possible that the full extent of the parasympathetic modulation of FF via respiration may be larger than found in the present study.

\section{Conclusions}

We found that slow controlled respiration causes cyclic alterations of AF rhythm at the respiratory frequency in patients with long lasting AF. The attenuation of this phenomenon by vagal blockade confirms that the observation is genuinely related to parasympathetic modulations of atrial electrophysiology. O ur utilization of paced patients with complete heart block excludes any mechanism related to autonomic effects on the atrioventricular node and the cancellation of ventricular components of the ECG out-rules contributions of ventricular depolarization to the spectral analysis. 


\section{ACKNOWLEDGEMENTS}

The authors would like to thank Prof S Bertil Olsson, Department of Cardiology, Lund University for valuable guidance in the preparation of the manuscript and Birgit Smideberg, Department of Cardiology, Lund University, for skilful technical assistance.

\section{GRANTS}

This study has been supported by grants from the Lund University, the Swedish Heart and Lung Foundation and the Bergquist foundation. The British Heart Foundation supported JEPW during this work. 


\section{REFERENCES}

1. Akselrod S, Gordon D, Madwed JB, Snidman NC, Shannon DC, and Cohen RJ. Hemodynamic regulation: investigation by spectral analysis. A m J Physiol 249: H867-875, 1985.

2. Akselrod S, Gordon D, Ubel FA, Shannon DC, Berger AC, and Cohen RJ. Power spectrum analysis of heart rate fluctuation: a quantitative probe of beat-to-beat cardiovascular control. Scienœ 213: 220-222, 1981.

3. Allessie MA, Lammers WJE P, Bonke FIM, and Hollen JM. Experimental evaluation of Moe's multiple wavelet hypothesis of atrial fibrillation. In: Cardiac electrophysiology and arrhythmias, edited by Zipes DP and Jalife J. O rlando, Florida: Grune \& Stratton, 1985, p. 265275.

4. Blaauw Y, Tieleman RG, Brouwer J, Van Den B, De Kam PJ, De Langen CD, Haaksma J, Grandjean JG, Patberg KW, Van Gelder IC, and Crijns HJ. Tachycardia induced electrical remodeling of the atria and the autonomic nervous system in goats. Paing Clin E lectrophysiol 22: 1656-1667, 1999.

\section{Calkins H, el Atassi R, Leon A, Kalbfleisch S, Borganelli M, Langberg J, and} Morady F. Effect of the atrioventricular relationship on atrial refractoriness in humans. Pading Clin E lectrophysiol 15: 771-778, 1992.

6. Campbell GD, Edwards FR, H irst GD, and $\mathbf{O}$ 'Shea JE. Effects of vagal stimulation and applied acetylcholine on pacemaker potentials in the guinea-pig heart. J Physiol (L ond) 415: 57-68, 1989. 


\section{Capucci A, Biffi M, Boriani G, Ravelli F, Nollo G, Sabbatani P, Orsi C, and}

Magnani B. D ynamic electrophysiological behavior of human atria during paroxysmal atrial fibrillation. Circulation 92: 1193-1202, 1995.

8. Chandler ST and Trewby PN. Is respiratory sinus arrhythmia present in atrial fibrillation? A study using two quantitative methods. M ed E ng P hys 16: 334-337, 1994.

\section{Cogliati C, Colombo S, Ruscone TG, Gruosso D, Porta A, Montano N, Malliani}

A, and Furlan R. Acute beta-blockade increases muscle sympathetic activity and modifies its frequency distribution. Circulation 110: 2786-2791, 2004.

\section{Coumel P, Hermida JS, Wennerblom B, Leenhardt A, Maison-Blanche $\mathbf{P}$, and}

Cauchemez B. Heart rate variability in left ventricular hypertrophy and heart failure, and the effects of beta-blockade. A non-spectral analysis of heart rate variability in the frequency domain and in the time domain. E ur H eart J 12: 412-422, 1991.

11. Denes $\mathbf{P}$. The effect of cycle length on the atrial refractory period. Pacing Clin E lectrophysiol 7: 1108-1114, 1984.

12. Furlan R, Guzzetti S, Crivellaro W, Dassi S, Tinelli M, Baselli G, Cerutti S, Lombardi F, Pagani M, and Malliani A. Continuous 24-hour assessment of the neural regulation of systemic arterial pressure and $\mathrm{RR}$ variabilities in ambulant subjects. Circulation 81: 537-547, 1990.

13. Goette A, Honeycutt C, and Langberg JJ. Electrical remodeling in atrial fibrillation. Time course and mechanisms. Circulation 94: 2968-2974, 1996. 
14. Holm M, Pehrson S, Ingemansson M, Smideberg B, Sörmo L, and Olsson SB.

Non-Invasive Assessment of the A trial Cycle Length during Atrial Fibrillation in Man. Introducing, Validating and Illustrating a New ECG Method. Cardiovasc Res 38: 69-81, 1998.

\section{Huikuri HV, Poutiainen AM, Makikallio TH, Koistinen MJ, Airaksinen KE,} Mitrani RD, Myenburg RJ, and Castellanos A. D ynamic behavior and autonomic regulation of ectopic atrial pacemakers. Circulation 100: 1416-1422, 1999.

16. Ingemansson MP, Holm M, and Olsson SB. Autonomic modulation of the atrial cycle length by the head up tilt test: non-invasive evaluation in patients with chronic atrial fibrillation. H eart 80: 71-76, 1998.

17. Inoue $\mathbf{H}$ and Zipes DP. Changes in atrial and ventricular refractoriness and in atrioventricular nodal conduction produced by combinations of vagal and sympathetic stimulation that result in a constant spontaneous sinus cycle length. Circ Res 60: 942-951, 1987.

18. Kim KB, Rodefeld MD, Schuessler RB, Cox JL, and Boineau JP. Relationship between local atrial fibrillation interval and refractory period in the isolated canine atrium. Circulation 94: 2961-2967, 1996.

19. Konings K, Kirchhof CJHJ, Smeets JRLM, Wellens HJJ, Penn OC, and Allessie MA. High-density mapping of Electrically Induced Atrial Fibrillation in Humans. Circulation 89: 1665-1680, 1994.

20. Lievre M, Ollagnier M, Timour-Chah Q, Descotes J, and Faucon G. Effects of mild hyperkalemia on conduction velocity and effective refractory period in various parts of the 
dog heart in situ. N aunyn Schmiedebergs A rch Pharmaool 313: 237-242, 1980.

21. Liu L and Nattel S. Differing sympathetic and vagal effects on atrial fibrillation in dogs: role of refractoriness heterogeneity. A m J Physiol 273: H805-816, 1997.

22. Löffenholtz K and Pappano AJ. The parasympathetic neuroeffector junction of the heart. Pharmacological Reviews 37: 1-24, 1985.

23. Meijler FL, Jalife J, Beaumont J, and Vaidya D. AV nodal function during atrial fibrillation: the role of electrotonic modulation of propagation. J Cardiovasc E lectrophysiol 7: 843861, 1996.

24. Meurling CJ, Ingemansson MI, Roijer A, Carlson J, Lindholm CJ, Smideberg B, Sörnmo L, Stridh M, and Olsson SB. Attenuation of electrical remodelling in chronic atrial fibrillation following oral treatment with verapamil. E uropaœ 1: 234-241, 1999.

25. Meurling CJ, Waktare JE, Holmqvist F, Hedman A, Camm AJ, Olsson SB, and Malik M. Diurnal variations of the dominant cycle length of chronic atrial fibrillation. A m J Physiol H eart Circ Physiol 280: H401-406, 2001.

26. Pagani M, Lombardi F, Guzzetti S, Rimoldi O, Furlan R, Pizzinelli P, Sandrone G, Malfatto G, Dell'Orto S, Piccaluga E, and et al. Power spectral analysis of heart rate and arterial pressure variabilities as a marker of sympatho-vagal interaction in man and conscious dog. Circ Res 59: 178-193, 1986.

27. Pehrson S, Holm M, Meurling C, Ingemansson M, Smideberg B, Sörnmo L, and Olsson SB. Non-invasive assessment of magnitude and dispersion of atrial cycle length during 
chronic atrial fibrillation in man. E ur H eart J 19: 1836-1844, 1998.

\section{Pomeranz B, Macaulay RJ, Caudill MA, Kutz I, Adam D, Gordon D, Kilbom KM,} Barger AC, Shannon DC, Cohen RJ, and et al. Assessment of autonomic function in humans by heart rate spectral analysis. A m J Physiol 248: H151-153, 1985.

29. Pop T and Fleischmann D. Alternans in human atrial monophasic action potenial. Br H eart J 39: 1273-1275, 1977.

30. Randall WC. Sympathetic modulation of normal cardiac rhythm. In: Cardiac electrophysiology, edited by Rosen MR, Janse MJ and Wit AL. Mount Kisco, New York, USA: Futura, 1990, p. 889-901.

31. Rensma PL, Allessie MA, Lammers WJ, Bonke FI, and Schalij MJ. Length of excitation wave and susceptibility to reentrant atrial arrhythmias in normal conscious dogs. Circ Res 62: 395-410, 1988.

32. Stridh M, Sörnmo, L., Meurling, C.J., O lsson, S.B. Sequential Characterization of Atrial Tachyarrhythmias Based on ECG Time-Frequency Analysis. Biomedical E nginearing, IE E E Transactions on 51: 100-114, 2004.

33. Stridh M. SL. Spatiotemporal Q RST cancellation techniques for analysis of atrial fibrillation. Biomedical E ngineering, IE E E Transactions on 48: 105-111, 2001.

34. van den Berg MP, Crijns HJ, Haaksma J, Brouwer J, and Lie KI. A nalysis of vagal effects on ventricular rhythm in patients with atrial fibrillation. Clin Sai (C olch) 86: 531-535, 1994. 
35. van den Berg MP, Haaksma J, Brouwer J, Tieleman RG, Mulder G, and Crijns

HJ. Heart rate variability in patients with atrial fibrillation is related to vagal tone. Circulation 96: 1209-1216, 1997.

36. Wijffels MCEF, Kirchhof CJHJ, Dorland R, and Allessie MA. Atrial fibrillation begets atrial fibrillation: A study in awake chronically instrumented goats. Circulation 92: 19541968, 1995.

37. Zipes DP, Mihalick MJ, and Robbins GT. Effects of selective vagal and stellate ganglion stimulation on atrial refractoriness. Cardiovasc Res 8: 647-655, 1974. 


\section{FIGURE LEGENDS}

Figure 1 - Schematic illustration of the derivation of the modulation spectrum of the ECG, via QRST-subtraction and two subsequent fast Fourier transforms (FFT).

The original ECG (a) is subsequently subjected to pacemaker spike removal (b) and QRST cancellation (c). By repeated measurements of the continuous recording a time-frequency distribution is obtained (d) from which the frequency trend is extracted (e). A final fast Fourier transform produces the modulation spectra of the different study phases (f).

Figure 2 - Response to controlled respiration, changes in $\mathrm{P}_{0.125} / \mathrm{P}_{\mathrm{HF}} .{ }^{*} \mathrm{p}=0.01, \dagger \mathrm{p}=\mathrm{NS}$. Wilcoxon matched pairs test.

Figure 3 - Example of modulation spectrum (patient a). The modulation spectra of the three different phases of the study are individually plotted. A clear peak at the frequency of respiration $(0.125 \mathrm{~Hz})$ is evident during the controlled respiration (CR) phase. It is not visible at baseline (B) and in spite of the same respiration pattern the peak is abolished following atropine administration (PA), suggesting a parasympathetic origin. 


\section{TABLES}

\section{TABle 1. PATIEnt Characteristics.}

\begin{tabular}{|c|c|c|c|c|c|c|c|c|}
\hline Patient & $\begin{array}{l}\text { Age } \\
\text { (years) }\end{array}$ & $\operatorname{Sex}$ & EF\% & $\begin{array}{c}\text { Left atrial } \\
\text { diameter (mm) }\end{array}$ & $\begin{array}{c}\text { AF Duration } \\
\text { (months) }\end{array}$ & $\begin{array}{l}\text { Number of } \\
\text { cardioversions }\end{array}$ & $\begin{array}{c}\text { Heart active } \\
\text { drugs }\end{array}$ & Co-Modbidity \\
\hline $\mathbf{a}$ & 62 & Female & 55 & 41 & 7 & 10 & diltiazem & none \\
\hline $\mathbf{b}$ & 64 & Male & 45 & 43 & 5 & 15 & none & COPD \\
\hline $\mathbf{C}$ & 65 & Female & 35 & 37 & 9 & 4 & metoprolol & $\mathrm{HT}, \mathrm{CHF}$ \\
\hline d & 64 & Female & 55 & 32 & 30 & 4 & none & none \\
\hline $\mathbf{e}$ & 54 & Male & 55 & 46 & 24 & 7 & losartan & none \\
\hline $\mathbf{f}$ & 59 & Male & 55 & 53 & 32 & 10 & losartan & $\mathrm{HT}$ \\
\hline $\mathbf{g}$ & 68 & Female & 55 & 45 & 7 & 26 & spironolactone & none \\
\hline $\mathbf{h}$ & 53 & Male & 55 & 32 & 24 & 7 & enalapril & $\mathrm{HT}$ \\
\hline
\end{tabular}

AF, atrial fibrillation; CHF, chronic heart failure ; COPD, chronic obstructive pulmonary disease; EF, ejection fraction; HT, Hypertension 


\section{TABLE 2 MEASURED PARAMETERS.}

\begin{tabular}{|c|c|c|c|c|c|c|}
\hline & \multicolumn{2}{|c|}{ BASELINE } & \multicolumn{2}{|c|}{ Controlled Respiration } & \multicolumn{2}{|c|}{ Post Atropine } \\
\hline & median & (range) & median & (range) & median & (range) \\
\hline Mean arterial Blood pressure (mmHg) & 90 & $(83-105)$ & 92 & $(82-103)$ & 92 & $(78-103)$ \\
\hline Fibrillation frequency $(\mathrm{Hz})$ & 6.9 & $(6.1-8.2)$ & 7.0 & $(6.0-8.2)$ & 6.8 & $(6.1-8.0)$ \\
\hline High frequency power (0.15-0.4 Hz band, ms²) & 0.13 & $(0.03-0.21)$ & 0.10 & $(0.05-0.34)$ & 0.11 & $(0.08-0.86)$ \\
\hline Low frequency power $\left(0.04-0.15 \mathrm{~Hz}\right.$ band, $\left.\mathrm{ms}^{2}\right)$ & 0.24 & $(0.11-0.36)$ & 0.20 & $(0.13-0.60)$ & 0.24 & $(0.09-0.52)$ \\
\hline [High freq.] / [Low freq.] & 0.49 & $(0.31-0.67)$ & 0.49 & $(0.39-0.59)$ & 0.68 & $(0.18-1.1)$ \\
\hline Total power $\left(0.04-0.4 \mathrm{~Hz}, \mathrm{~ms}^{2}\right)$ & 0.17 & $(0.06-0.25)$ & 0.13 & $(0.07-0.42)$ & 0.15 & $(0.08-0.40)$ \\
\hline Power at $0.125 \mathrm{~Hz}\left(\mathrm{~ms}^{2}\right)$ & 0.15 & $(0.06-0.25)$ & $0.36^{*}$ & $(0.11-0.58)$ & $0.13^{\ddagger}$ & $(0.02-0.42)$ \\
\hline Power at $0.125 \mathrm{~Hz} /$ High frequency power & 1.4 & $(0.76-2.0)$ & $2.7^{*}$ & $(1.2-5.8)$ & $1.2^{\dagger}$ & $(0.23-2.8)$ \\
\hline
\end{tabular}

Pairs Test) 
TABLE 3. CHANGES IN POMER AT THE FREQUENCY OF CONTROLLED RESPIRATION.

\begin{tabular}{cccc}
\hline Patient & Baseline & Controlled Respiration & Post Atropine \\
& $\mathbf{P}_{\mathbf{a n d}} \mathbf{P}_{\mathbf{H F}}$ & $\mathbf{P}_{\mathbf{a n d}} \mathbf{P}_{\mathbf{H F}}$ & $\mathbf{P}_{\mathbf{a n d}} \mathbf{P}_{\mathbf{H F}}$ \\
\hline $\mathbf{a}$ & 1,00 & 5,76 & 0,23 \\
$\mathbf{b}$ & 1,85 & 2,43 & 1,73 \\
$\mathbf{C}$ & 1,83 & 2,39 & 0,80 \\
$\mathbf{d}$ & 2,01 & 2,93 & 1,85 \\
$\mathbf{e}$ & 1,85 & 4,21 & 2,83 \\
$\mathbf{f}$ & 0,95 & 1,23 & 1,03 \\
$\mathbf{g}$ & 1,05 & 3,63 & 1,33 \\
$\mathbf{h}$ & 0,76 & 2,42 & 0,27 \\
\hline
\end{tabular}

All values represent the absolute values of power calculated at the frequency of respiration divided by the mean power value in the high frequency band $\left(\mathrm{P}_{0.125} / \mathrm{P}_{\mathrm{HF}}\right)$. 
a

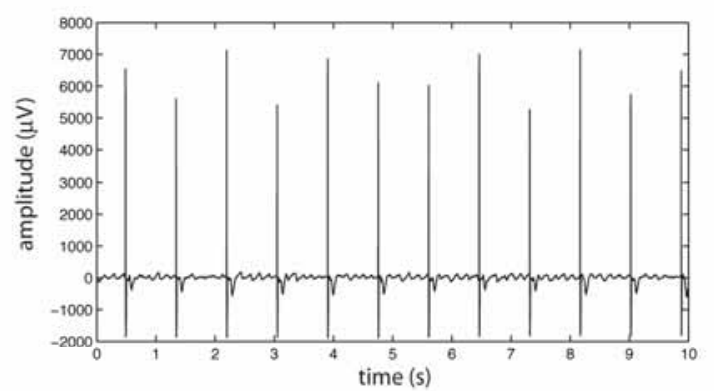

Original ECG (10 sec)

b

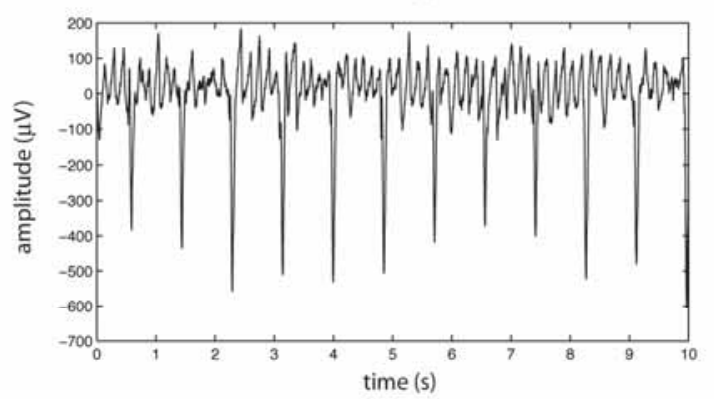

After pacemaker spike removal $(10 \mathrm{sec})$

After QRST cancellation (10 sec)

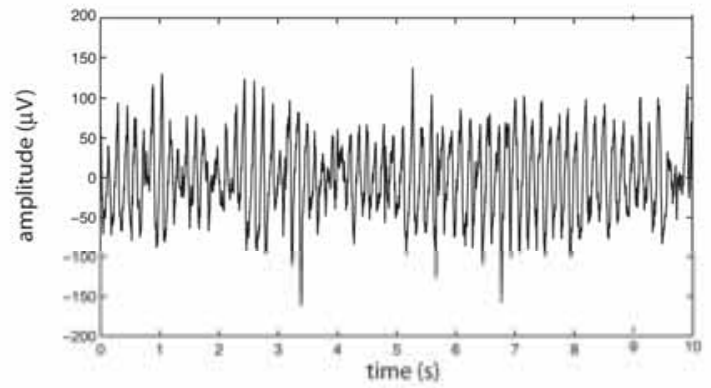

d

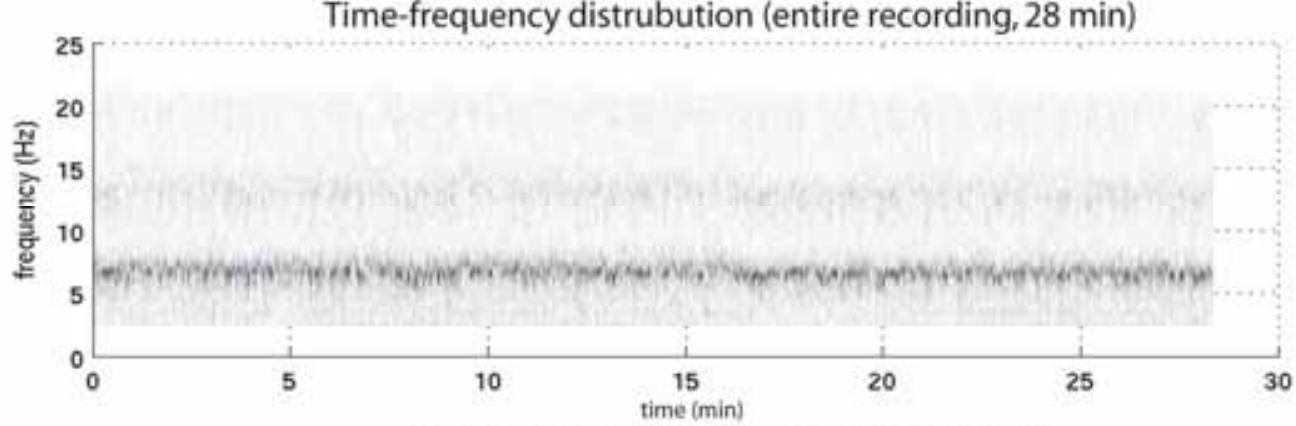

Frequency trend (entire recording, $28 \mathrm{~min}$ )

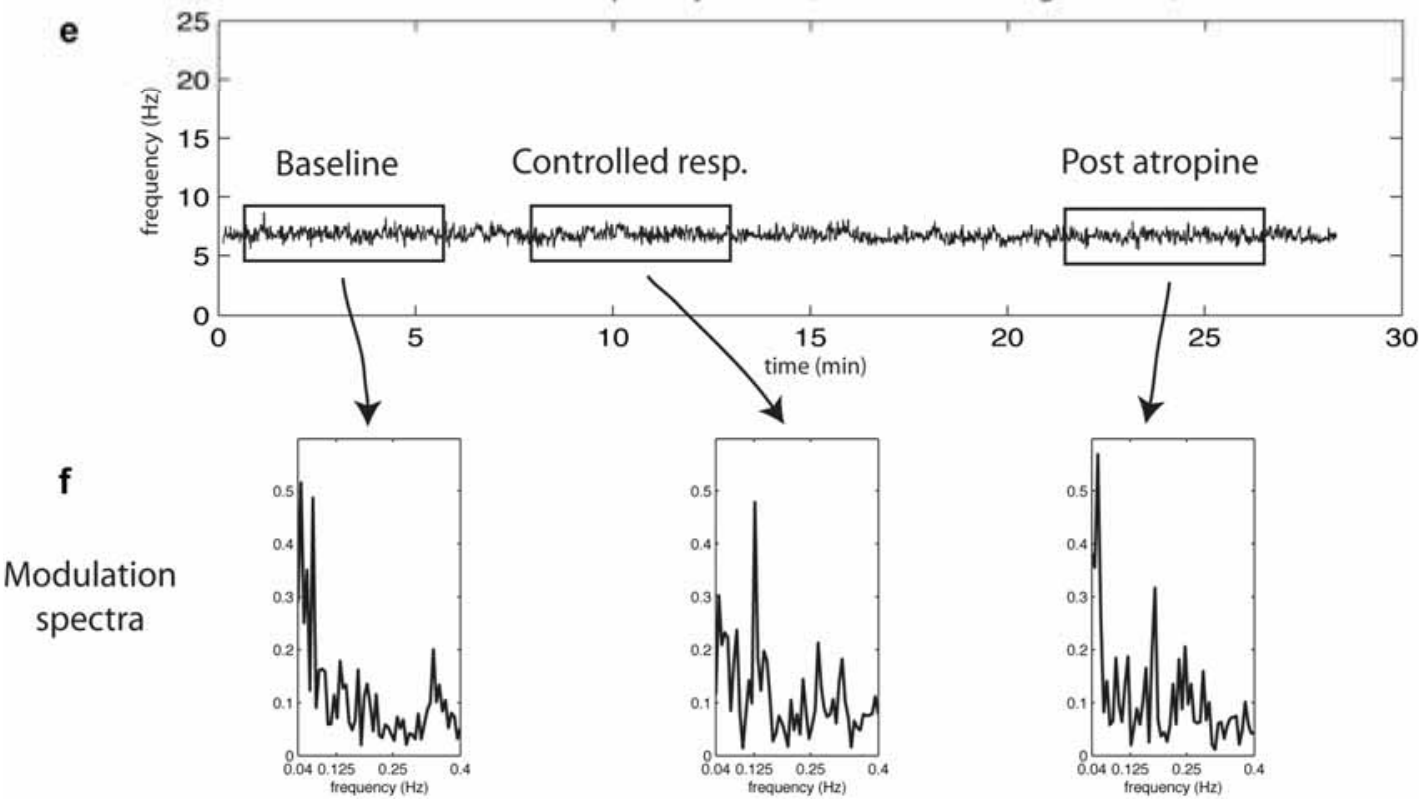


FIGURE 2

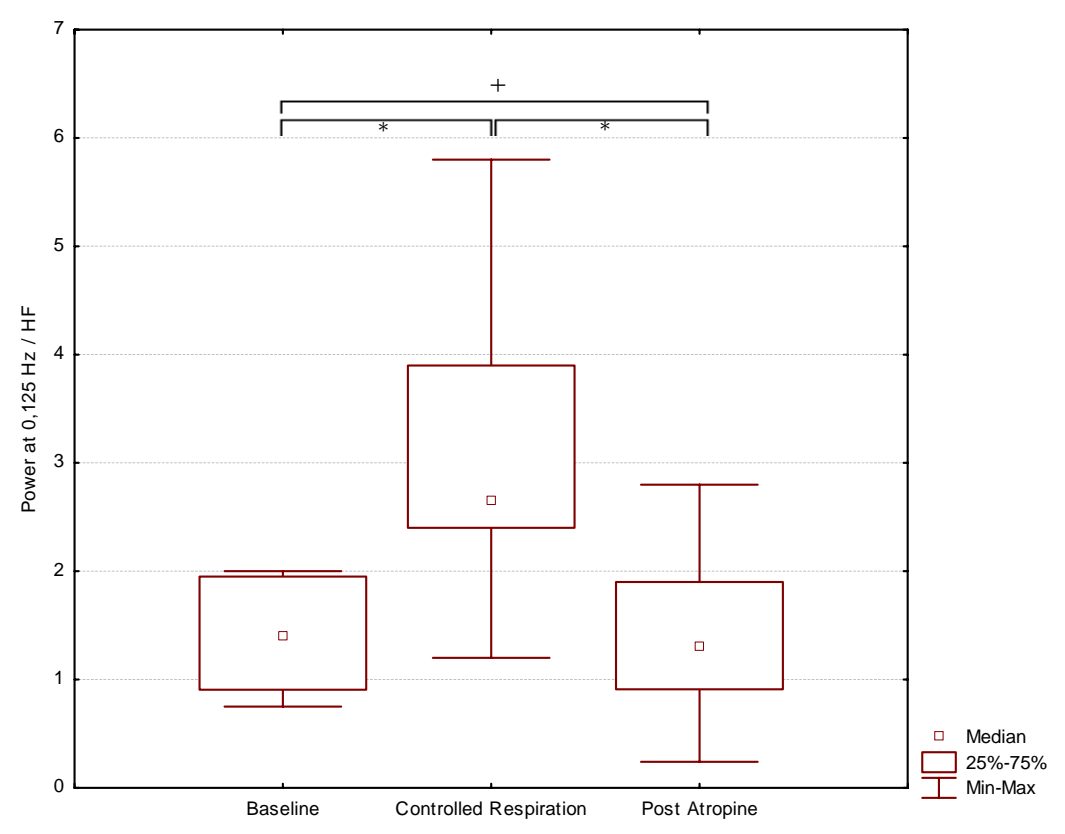

FIGURE 3
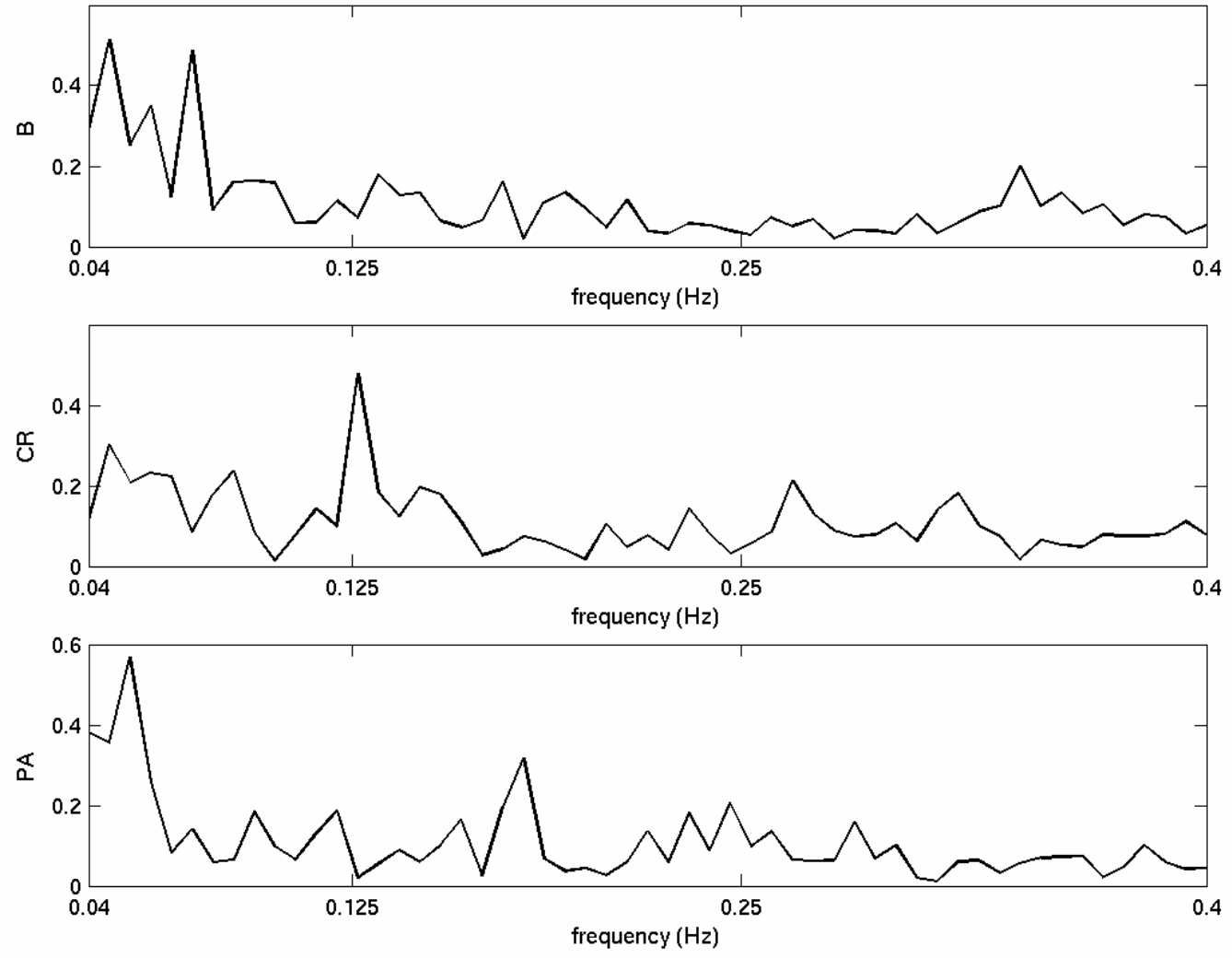